\title{
Evaluation of Approval Request/Call for Release Coordination Procedures for Charlotte Douglas International Airport
}

\author{
Lindsay Stevens \\ NASA Ames Research Center \\ Moffett Field, CA, USA \\ lindsay.stevens@nasa.gov
}

\author{
Lynne Martin \\ NASA Ames Research Center \\ Moffett Field, CA, USA
}

Eric Chevalley

San Jose State University

At NASA Ames Research Center

Moffett Field, CA, USA

\author{
Hanbong Lee \\ NASA Ames Research Center \\ Moffett Field, CA, USA
}

\author{
Kimberly Jobe \\ San Jose State University \\ At NASA Ames Research Center \\ Moffett Field, CA, USA
}

\author{
Savita Verma \\ NASA Ames Research Center \\ Moffett Field, CA, USA
}

\author{
Bonny Parke \\ San Jose State University \\ At NASA Ames Research Center \\ Moffett Field, CA, USA
}

\author{
Victoria Dulchinos \\ San Jose State University \\ At NASA Ames Research Center \\ Moffett Field, CA, USA
}

\begin{abstract}
NASA is collaborating with the Federal Aviation Administration (FAA) and aviation industry partners to develop and demonstrate new concepts and technologies for Integrated Arrival, Departure, and Surface (IADS) traffic management capabilities under the Airspace Technology Demonstration 2 (ATD-2) project. One of the goals of the IADS capabilities in the ATD-2 project is to increase predictability and throughput of airspace operations by improving Traffic Management Initiative (TMI) compliance. This paper focuses on the Approval Request (APREQ) procedures developed for the ATD-2 project between the Air Traffic Control (ATC) Tower at Charlotte Douglas International Airport and Washington Center. In March 2017, NASA conducted a Human-in-the-Loop (HITL) simulation to evaluate the operational procedures and information requirements for the APREQ procedures in the ATD-2 IADS system between ATC Tower and Center. The findings from the HITL are used to compare ATD-2 APREQ procedures with information about current day APREQ procedures.
\end{abstract}

Keywords-APREQ, call for release, procedures, electronic coordination

\section{INTRODUCTION}

Across the national airspace system (NAS), air traffic capacity and demand imbalances result in congestion and delays from multiple sources which can compound on individual flights, preventing timely departures. Flights are often subject to Traffic Management Initiatives (TMIs), both strategic and tactical, in order to alleviate delay at the source of congestion. Ground Delay Programs and Airspace Flow Programs are two widely used strategic TMIs resulting from capacity and demand imbalance on the airport surface or in the airspace, respectively. Both of these strategic TMIs result in the issuing of an Expect Departure Clearance Time (EDCT) to flights at their departure airports to control the flow of aircraft into these overburdened resources. EDCTs are accompanied by a $-5 /+5$ minute compliance window, meaning that a flight can depart the runway five minutes before or five minutes after the EDCT and still be in compliance with the EDCT [1]. One popular tactical TMI is the Approval Request (APREQ) / Call for Release (CFR). The APREQ/CFR is typically issued from Air Route Traffic Control Centers (ARTCCs, or "Centers") to departure flights at nearby airports which are ascending into congested overhead stream traffic. In these cases, flights are issued release times prior to departure that is accompanied by a $-2 /+1$ minute compliance window, or two minutes before or one minute after the APREQ release time. The compliance window favors early release of aircraft since it is easier to delay flights after takeoff than to make up time for later releases once airborne. In some cases, flights are issued multiple TMIs from various sources and incur additional delay.

Charlotte Douglas International Airport (CLT) faces unique challenges and its position in the NAS makes it prone to frequent Traffic Flow Management (TFM) constraints, like APREQs. CLT is situated beneath one of the busiest air traffic corridors on the eastern seaboard, between the Hartsfield-Jackson Atlanta International Airport (ATL; about 200 miles southwest), which is typically one of the busiest US airports, and the Washington D.C. metroplex (300 miles northeast). CLT is inside the Atlanta Center (ZTL) and is bordered by Washington Center (ZDC) and Jacksonville Center (ZJX). Its position near ZDC subjects CLT to not only TFM constraints from ZTL, but from ZDC as well.

A benefits analysis of CLT's 2014 operations [2] outlined some of the problems caused by TMI flights out of CLT in terms of delays and predictability. Flights with EDCT alone experienced an average of 3.2 minutes of additional taxi delay on the airport surface compared to flights without TMIs. The additional delay was even greater when multiple TMIs were 
issued to the same flight (e.g., EDCT + APREQ, APREQ + Miles-in-Trail [MIT]), with added delays of up to 6.8 minutes (the average for flights that each had both MIT and EDCT restrictions) beyond the taxi delay imposed on non-TMI flights. TMI compliance, a measure of predictability, at CLT for APREQ and EDCT flights was found to be $42.9 \%$ and $56.2 \%$, respectively, with NAS-wide compliance being $54.4 \%$ and $46.9 \%$, respectively. At CLT, flights that were under both APREQ and EDCT restrictions maintained similar compliance with the APREQ release times, but EDCT compliance fell to $52 \%$. This poor compliance may be a result of limited predictive information about surface traffic, estimated departure times, and the large volume of release times that must be negotiated, among other reasons. By improving the predictability of estimated departure times and increasing TMI compliance, more flights can be released from the airport surface and successfully inserted into the overhead stream of traffic.

Airspace Technology Demonstration 2 (ATD-2) technologies designed to automate the APREQ procedures are part of the new concepts and technologies that NASA is developing for Integrated Arrival, Departure, and Surface (IADS) in collaboration with the FAA. One of the goals of the IADS capabilities in the ATD-2 subproject is to increase predictability and throughput of airspace operations by improving TMI compliance. The IADS capabilities that will improve TMI compliance are built upon previous NASA research, in particular the Precision Departure Release Capability (PDRC) [3]. The ATD-2 IADS system will also provide a Terminal Flight Data Manager (TFDM) System Wide Information Management (SWIM) prototype data feed that will, among other things, populate TMI-related data for flights at CLT as well as information related to surface scheduling and other flight estimates. The ATD-2 IADS system also ingests other data feeds, such as the National Traffic Management Log (NTML), to provide users with the most up-to-date information about TMIs and other events.

Additionally, the ATD-2 IADS system integrates airlines data. The system then provides takeoff time predictions based on airlines' Earliest Off Block Times. The takeoff times will be communicated to TBFM/IDAC, thus providing estimated departure times based on predictions rather than airline scheduled p-times. These takeoff estimates help improve predictability during scheduling and increases chances of compliance.

This paper describes the current day APREQ/CFR procedures and introduces the APREQ/CFR procedures developed by ATD-2. These new procedures were used during a three-day simulation, described later in the paper. The findings of the simulation on the ATD-2 APREQ/CFR procedures are assessed in comparison with current day APREQ/CFR procedures.

\section{APREQ / CFR PROCEDURES: CURRENT DAY}

Current day procedures for APREQ/CFR coordination at CLT are done through verbal Call for Release. After the pilot calls Clearance Delivery (CD) in the Air Traffic Control (ATC) Tower at pushback, the ATC Tower staff (usually the TMC if he or she is on duty in the ATC Tower) calls the Center to request a release time for the flight. The ATC Tower informs the Center TMC of the flight's estimated take off time. The Center TMC schedules the flight to the meter point in the overhead stream by entering the desired scheduled time of arrival to the meter point in the Time Based Flow Management (TBFM) system. TBFM back-calculates a release time for the flight. The Center TMC then communicates the release time to the ATC Tower. The release time, unless otherwise communicated by the Center TMC, has a release compliance window that extends from two minutes prior to one minute after the scheduled departure time [1]. The ATC Tower passes the release time to $\mathrm{CD}$, who then informs the pilot of the release time. As the aircraft makes its way to the runway, the ATC Tower monitors the feasibility of the flight's ability to comply with release time. If the flight is determined to be late, the ATC Tower calls the Center TMC and negotiates a new release time for the flight. Fig. 1 provides a visual representation of the current day CFR procedures.

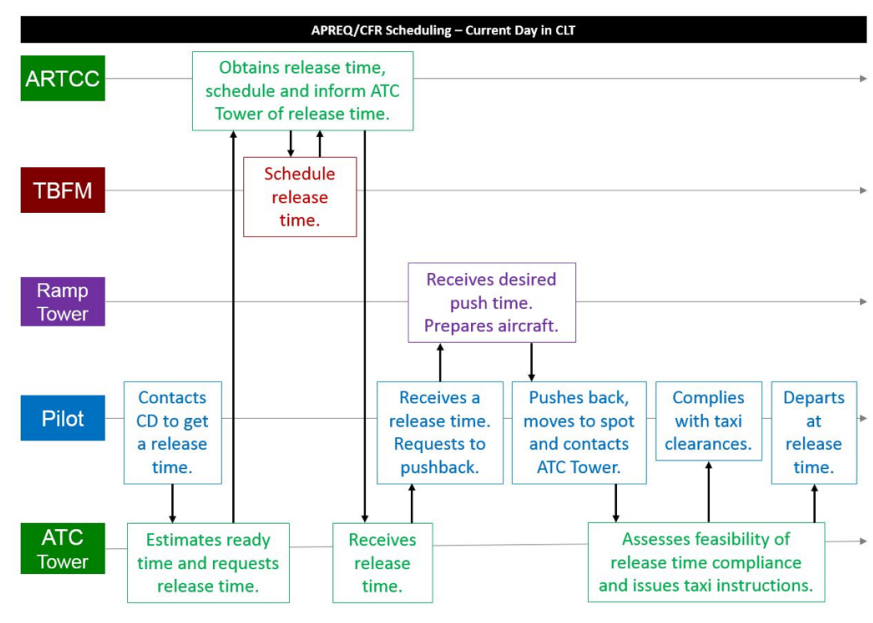

Fig. 1. Flow chart of current day APREQ/CFR procedures.

\section{APREQ / CFR PROCEDURES: ATD-2}

This section describes how APREQ/CFR restrictions enter the ATD-2/IADS system and the procedures for negotiating release times for flights in the Surface Trajectory Based Operations (STBO) Client as used during the simulation described in Section IV.

\section{A. APREQ Resriction Assignment in STBO Client}

There are two ways that APREQ restrictions can be assigned to a flight in the STBO Client. The first way a flight may obtain a restriction is via NTML. In current day operations, information about restrictions and other national airspace events are entered into NTML. Center TMCs can input APREQ/CFR restrictions for airports that have departing flights that will enter their airspace. CLT ATC Tower TMC can view the NTML to observe any restrictions that will be impacting CLT. The STBO Client will read these restrictions automatically from NTML and provide the ATC Tower TMC with notifications that a restriction is scheduled. It will then mark each flight in the system that is under the restriction.

There are some instances when a restriction is not reflected in the NTML. For example, flights from CLT to HartsfieldJackson Atlanta International Airport (ATL) are under CFR on 
a daily basis due to the heavy traffic into ATL. Since this is part of an agreed procedure between CLT and Atlanta Center (ZTL), there is no need for the CFR to be entered into NTML. Without this entry, ATD-2 automation cannot account for the restriction. In the event that a restriction is not entered into NTML or is not displayed in the ATD-2 tools, STBO Client will provide an input option for the ATC Tower TMC to manually schedule the restriction in the ATD-2 IADS system. A notification of each scheduled restriction will be sent out to all ATD-2 users, and where applicable, individual flights will be marked with the restriction.

\section{B. Electronic APREQ Coordination}

The first phase of the IADS Demonstration will be at CLT. During this first phase, the ATC Tower and the airline Ramp Tower will receive displays that allow them to engage with the IADS capabilities. In the ATC Tower, the ATD-2 technology will be placed at the Traffic Management Coordinator (TMC) work station and the primary users will be the TMC and, when the TMC is not on duty, the Front Line Manager (FLM). The ATC Tower users will receive the STBO Client as the primary ATD-2 display. The STBO Client provides situational awareness of surface traffic and uses a tactical departure scheduler to automate the APREQ/CFR coordination procedures. This tactical departure scheduler leverages the TBFM / Integrated Departure Arrival Capability (IDAC) Integrated Departure Scheduling Tool (IDST) for APREQ/CFR coordination between ATC Tower and Center. Like IDST, the STBO Client will allow users to view slots in the overhead stream on a runway timeline and submit electronic requests for release times for flights subject to APREQ restrictions through IDAC-enabled Centers [4]. STBO Client users will also have the added ability to manually input release times obtained through current day CFR procedures into the STBO Client and release times electronically coordinated with the Center while viewing other TMIs for a flight, such as an EDCT.

The STBO Client will also exchange data and integrate with other ATD-2 technologies. This will enable all ATD-2 users to be privy to the same information about flights, TMIs, and airport events. For example, information on APREQ release times will be shared with the Ramp Tower. The STBO Client can also be used to enter TMI restrictions (such as APREQ, MIT, and Ground Stops) and to provide additional input about airport operations that can be disseminated to the Ramp Tower and other ATD-2 users.

TBFM/IDAC has been deployed to ZDC and is being used for electronic APREQ coordination with 5 nearby ATC Towers using IDST. Since CLT will be using the STBO Client, data exchange between the STBO Client and TBFM/IDAC will need to resemble data exchange in IDAC IDST. Given the field ready state of IDAC IDST, the procedures for electronic coordination of APREQ release times using STBO Client are designed to emulate the procedures used in IDAC IDST electronic APREQ coordination.

APREQ/CFR restrictions for CLT can originate from two different Centers: ZTL and ZDC. If a Center is equipped with TBFM/IDAC, the Center can opt to accept electronic coordination of APREQ release times. During the first phase of the IADS demonstration, only ZDC will be able to engage in electronic coordination of APREQ release times. As such, a distinction must be made between flights that are capable of electronic coordination and flights that require verbal coordination of APREQ release times. If a "lightning bolt" symbol appears next to the flight datablock on the Timeline in STBO Client (Fig. 2), the flight may be scheduled an APREQ release time electronically.

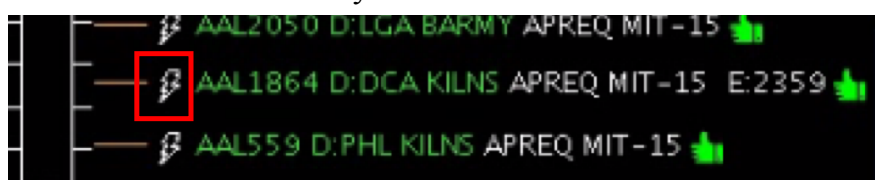

Fig. 2. Symbol for electronic coordination capability.

The ATC Tower user is given an indication (the "thumbs up" icon in Fig. 2) 10 minutes before a flight's Earliest Off Block Time (EOBT; an airline generated estimate of the earliest time that a flight will be ready for pushback, based on a variety of metrics, including passenger ticket scan). This symbol informs the ATC Tower user that the pilot will be ready for pushback and calling $\mathrm{CD}$ in the next ten minutes (approximately 30 minutes before takeoff) to obtain an APREQ release time.

Once the pilot calls, the ATC Tower user can electronically request an APREQ release time for the flight. To do this, the ATC Tower user right-clicks on the flight datablock on the STBO Client timeline. The user can then select one of two electronic coordination options: "Select Slot on Timeline" and "Request Release Time".

For each flight capable of electronic coordination of APREQ Release times, when the flight's datablock is selected, the STBO Client highlights available slots in the overhead stream for the flight in green and occupied slots in red on the center of the timeline (Fig. 3). These slots in the overhead stream correspond to the meter list for the meter point from TBFM/IDAC relevant to the selected flight. The STBO Client provides additional information on the EDCT and the EDCT $-5 /+5$ minute compliance windows. For flights subject to both APREQ and EDCT restrictions, ATC Tower users will be able to plan their requests for APREQ release times so that flights can comply with both restrictions, if possible.

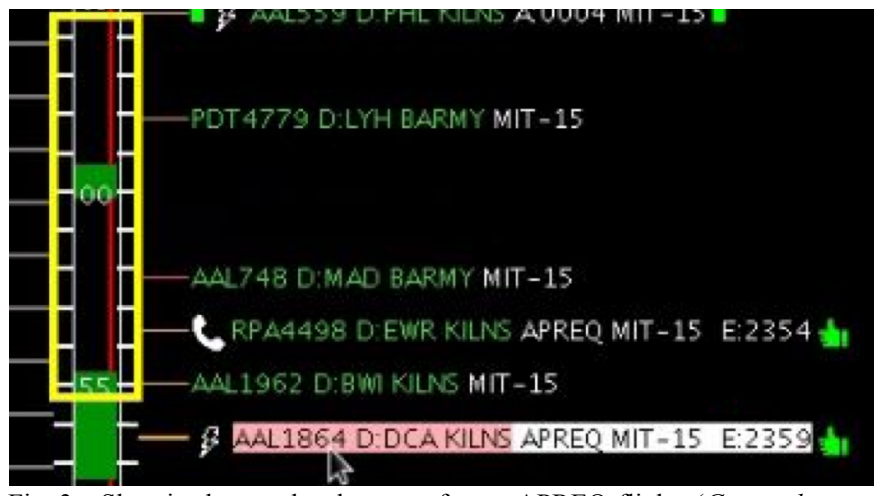

Fig. 3. Slots in the overhead stream for an APREQ flight. (Green slots are available to the APREQ flight, red slots are occupied and unavailable. The yellow box is a visual representation of the EDCT compliance window for the flight..) 


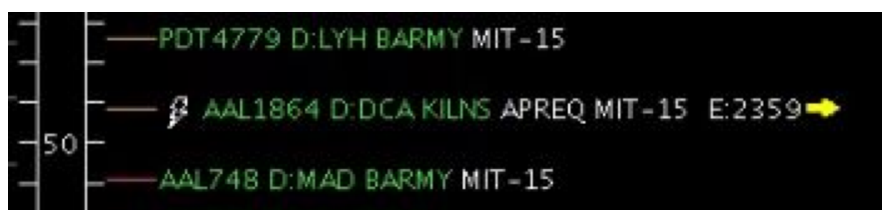

Fig. 4. Request for an APREQ release time has been sent to Center.

The "Select Slot on Timeline" option allows the user to choose from available slots in the overhead stream to generate a release time to request from Center. With the flight datablock selected, the user can choose the "Select Slot on Timeline" option and then click on an available slot on the timeline. The time on the timeline that corresponds to the user's click is transmitted to the Center as the requested release time for the flight. A yellow arrow appears to the right of the flight's datablock to indicate that the request has been sent (Fig. 4).

The alternative "Request Release Time" option is a method of requesting a release time from the Center without the user having to input any time into the system. Instead, the automation in the STBO Client selects the earliest feasible departure time that the aircraft is predicted to meet, accounting for the slot availability in the overhead stream, and sends a request for the flight's departure at its earliest departure time to the Center. Like in the "Select Slot on Timeline" option, a yellow arrow symbol notifies the user that the request has been sent.

After a request for a release time is sent to Center using either method, the Center TMC may accept the requested release time, input a new time that differs from the requested release time, or cancel the request altogether.

When the release time is sent back from Center, a new symbol (Fig. 5) appears next to the flight's datablock to indicate the newly assigned release time. STBO Client requires an acknowledgment from the ATC Tower user that the time was received. The ATC Tower user's acknowledgment completes the scheduling process for the APREQ release time.

Once an APREQ release time is scheduled, compliance indicators appear on either side of the flight's datablock on the timeline. The compliance indicators are color-coded blocks that inform the user about a flight's ability to meet the compliance window for APREQ flights and EDCT flights. Compliance indicators change between green, red, and yellow to indicate if the flight will meet the compliance window, be outside of the compliance window and late, or be outside of the compliance window and early, respectively. For a flight with only an APREQ or only an EDCT restriction, the compliance indicators are to indicate the flight's ability to meet the compliance window for that restriction. If a flight has both an APREQ and EDCT restriction, the compliance indicators reference the APREQ compliance window and do not appear next to the flight's datablock on the timeline until the flight has an assigned APREQ release time.

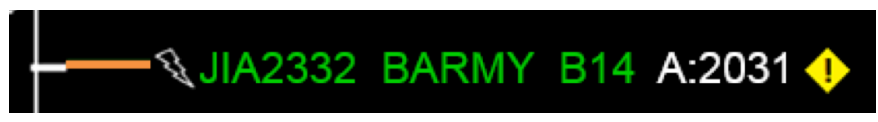

Fig. 5. Symbol that indicates that a release time has been returned from Center and needs to be acknowledged.
If at any time the ATC Tower user wishes to request a different APREQ release time for a flight, the user can cancel the current APREQ and begin a new round of APREQ coordination with the Center. Numerous iterations of the electronic APREQ coordination processes are possible and the ATC Tower user always has the option to call the Center and verbally coordinate a release time for any APREQ flight.

\section{Verbal Call for Release Coordination}

If a telephone symbol appears on a timeline datablock for a flight that is subject to an APREQ, as shown in Fig. 6, Center is unable to or is opting to not receive electronic requests for release times. In this case, the release time must be negotiated verbally via a telephone call to the Center TMC using the same procedures as described for current day operations.

Generally, after the release time is negotiated between the ATC Tower TMC and Center TMC, the Center TMC will enter the release time into TBFM and the release time will be populated through SWIM to the STBO Client display. However, if this time is not entered by the Center or if the time does not appear on the STBO Client display, it will be necessary for the ATC Tower TMC to enter this release time into the system manually to ensure all ATD-2 users are aware of the flight's release time. This is accomplished by opting to "Set Release Time". After inputting the negotiated release time, the ATC Tower TMC will click "Set Time", as shown in Fig. 6, to complete the entry.

Once the APREQ/CFR release time is entered into the system, the release time will be disseminated throughout the various windows on the STBO Client display as well as to the ATD-2 decision support tool provided to the Ramp Manager Traffic Console (RMTC) display in the Ramp Tower.

In the event that a new release time must be coordinated for a flight, the ATC Tower TMC can renegotiate a time verbally with the Center TMC and then make a new manual entry of the APREQ/CFR release time into the system. It should be noted that the manual entry of a CFR release time is available for all flights under an APREQ/CFR restriction, even for those flights that have the lightning bolt symbol indicating the capability for electronic negotiation.

The objective of this study was to test the ATD-2 APREQ electronic and verbal procedures and obtain feedback from users. The method used in this simulation is described in Section IV.

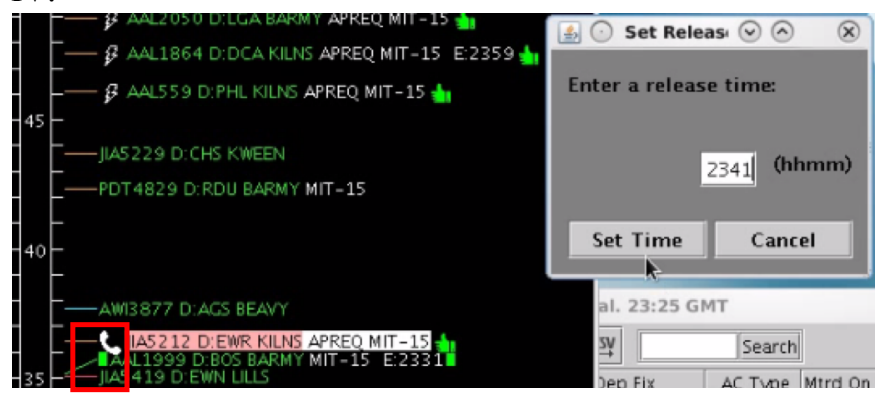

Fig. 6. Verbal CFR coordination. (On the right is an example of a manual entry of a CFR release time which was coordinated verbally between CLT Tower TMC and ZDC TMC for the highlighted flight.) 


\section{METHOD}

A Human-in-the-Loop (HITL) simulation was utilized to demonstrate the effects of metering traffic from pushback at the Ramp into overhead streams of traffic (described in [5]) and to gain user feedback on new departure management tools including electronic APREQ coordination. These new tools and scheduling capabilities were provided on custom displays in both the Ramp Tower and the ATC Tower.

In the HITL, participants worked in four different simulated facilities, including the airline Ramp Tower at CLT, CLT ATC Tower, CLT Terminal Radar Approach Control (TRACON), and ZDC. The methods for the ATC Tower and ZDC in the HITL are described below. Both departure and arrival metering (scheduling traffic to meet a pre-planned schedule or time at a designated physical point) was available in all simulation runs. In addition, the airport configuration was varied between north and south. Two simulation scenarios were built, one for Northflow traffic and one for South-flow traffic. The North scenario contained six APREQ/CFR flights, two of which also had an EDCT restriction, and the South scenario had eight APREQ/CFR flights, two of which had an EDCT restriction as well. The scenarios did not include winds or weather information. Each simulation session lasted for approximately an hour.

\section{A. Air Traffic Control Tower}

1) Tower ground-space and scenarios: The simulated CLT ATC Tower was staffed as six positions, with four controller participants managing the active movement area (i.e., taxiways and runways), one TMC participant, and one Clearance Delivery confederate. The ATC Tower is located just to the north of the passenger terminal at CLT, see Fig. 6, hence controllers look out and work facing south. Charlotte airport has three parallel north-south runways, where the west runway $(18 \mathrm{R} / 36 \mathrm{~L})$ is used predominantly for arrivals, the center runway $(18 \mathrm{C} / 36 \mathrm{C})$ is used during busy times predominantly for departures but also accommodates heavy aircraft, and the east runway $(18 \mathrm{~L} / 36 \mathrm{R})$ interleaves arrivals and departures. The fourth crossing runway $(23 / 5)$ is used for arrivals under some South-flow configurations.

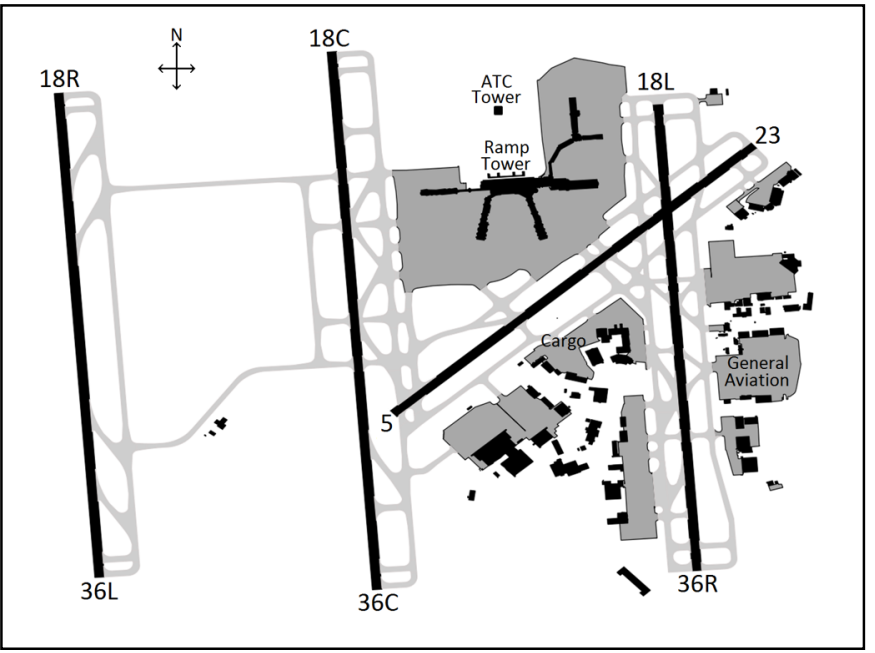

Fig. 7. Map of CLT. (map of CLT displaying runways, ramp areas, and ATC Tower)
The ATC Tower was simulated in a medium fidelity tower laboratory in the NASA Future Flight Central (FFC), using eight 40 " monitors to give a 270 degree out-the-window view to the south, i.e., over the airport. The monitors were set up with a "seamless" view that provided continuity across the eight screens. There were four controller stations around this tower view, with the Local Control East on the left, then two Ground Controllers (East and West), and the Local Control Center/West as the last position on the right. Each controller had a monitor on the desk in front of them which displayed the STBO Client map view. For this group, the STBO Client displays only enabled the adjustment of map settings with no features that provided input into the ATD-2 tools. The displays were intended to be a substitute for Airport Surface Detection EquipmentModel X (ASDE-X), which is available in the ATC Tower at CLT.

Controllers had a simulated radio communication application with a headset, so they could talk to their pilots and other controllers, and access to paper flight-strips. The traffic was generated by the Airspace Traffic Generator (ATG) [6] and was rendered on the out-the-window monitors through the modeling software that drove the Ramp view. CD was seated behind the Local Control East controller and the TMC station was situated behind $\mathrm{CD}$. $\mathrm{CD}$ had a simulated audio/voice connection into the frequencies that the other controllers were talking on and handled the paper flight-strips. The TMC had two displays, on 27" vertical monitors, driven by the STBO tool. The first had a map of CLT showing traffic on the active movement area, and a second monitor showed the departure and arrival timelines for CLT. The situational display used as the Ramp tool during the simulation was also available, but it shared the monitor that displayed the STBO map, and TMCs often fully overlaid one on top of the other so that only one could be viewed at a time. The TMC had a telephone that he could use to call the ZDC TMC.

The active movement area at CLT is a complex space to work. The arrival-departure bank system loads some taxiway junctions with arriving and departing traffic, and queues at the north end of the taxiway $\mathrm{C}$ (which runs parallel to runway $18 \mathrm{~L} / 36 \mathrm{R}$, between the runway and the ramp) can add to congestion difficulties on the east side of the ramp. Simulation scenarios for the ATC Tower received departing traffic from the Ramp and arriving traffic from the TRACON. The North-flow scenario had traffic fed to controllers at a rate of 75 arrivals and 65 departures per hour. In the South-flow scenario, traffic was fed at a rate of 92 arrivals and 80 departures per hour. These rates match rates at CLT in the operational environment. The TMC and CD had the primary role of scheduling the six aircraft in the North-flow scenario and eight departures in the Southflow scenario that needed to have APREQ release times arranged.

2) Tower participants: Five retired controllers took part in the simulation as confederates and four active Traffic Managers and Front Line Managers from CLT rotated through the TMC position. Controller participants' years of experience (excluding training) ranged from 18-31 years $(M=24.6, S D=$ 4.7). Four had worked at CLT and one in Los Angeles International Airport ATC Tower. The controllers rotated through their positions but the $\mathrm{CD}$ confederate position was 
staffed by the same person for the duration of the simulation. The four active personel had 29.6 years of experience as controllers, on average, and an additional 6.7 (average) years of experience as TMCs, ranging from 6-8 years performing TMC duties.

The controller participants were supported by four pseudo pilots who were paired with them, and who completed standard pilot taxi and takeoff tasks, controlling the aircraft in accordance with controller instructions and responding to communications.

3) Tower procedures: Tower participants were asked to work the traffic as they would in the field, trying to maximize throughput, while ensuring safety, and launch aircraft with APREQ or EDCT times on time.

The TMC's primary role was to set up and manage these APREQ times, coordinating with the ZDC TMC to arrange a mutually acceptable schedule. The TMC used the STBO Client to send an electronic request to schedule an APREQ (as described above) and to make adjustments to this time later during a run, if necessary. Clearance Delivery ensured that the Tower controllers received these scheduled release times on their paper flight-strips. Controllers then relay the time to the pilots.

\section{B. ARTCC}

1) ARTCC airspace and scenarios: One ZDC TMC position was staffed in the simulation. ZDC is a busy Center located to the north of the Atlanta Center, and CLT is located under the major routes to/from ZDC, as shown in Fig. 8. A number of other major airports are likewise located below ZDC, however, and are served by it, including Baltimore, Dulles and Washington National. It is divided into eight areas with 25 sectors, but none of these were represented in this study.

The ZDC TMC was simulated in the NASA Airspace Operation Lab (AOL) as a single workstation with three 30" screens. The TMC viewed the STBO tool displayed on one monitor, showing the CLT map view, and hence traffic movements at CLT and the CLT departure/arrival timelines. On another monitor, TMCs displayed TBFM schedules/timelines for all the airports that were being metered-to (La Guardia, Dulles, Washington National, Newark, Baltimore, Philadelphia and Kennedy) on a series of layered views. The Traffic Situation Display was shown on the third monitor, to the left of the TMC participant, giving a view of the traffic flowing into and out of the CLT TRACON. The TMC also had a telephone, so that he could talk to the CLT Tower TMC and other towers. The en route traffic was generated by the Multi-Aircraft Control System (MACS) simulation software [7] and information from this system was fed into STBO.

The ZDC TMC role is complex; the ZDC airspace is responsible for traffic to/from its own major airports, as well as significant traffic in transition (ascending and descending) to reach major airports in the northeast which are located in close proximity to one another, e.g., the New York area airports, in much smaller airspace (e.g., New York ARTCC [ZNY]).

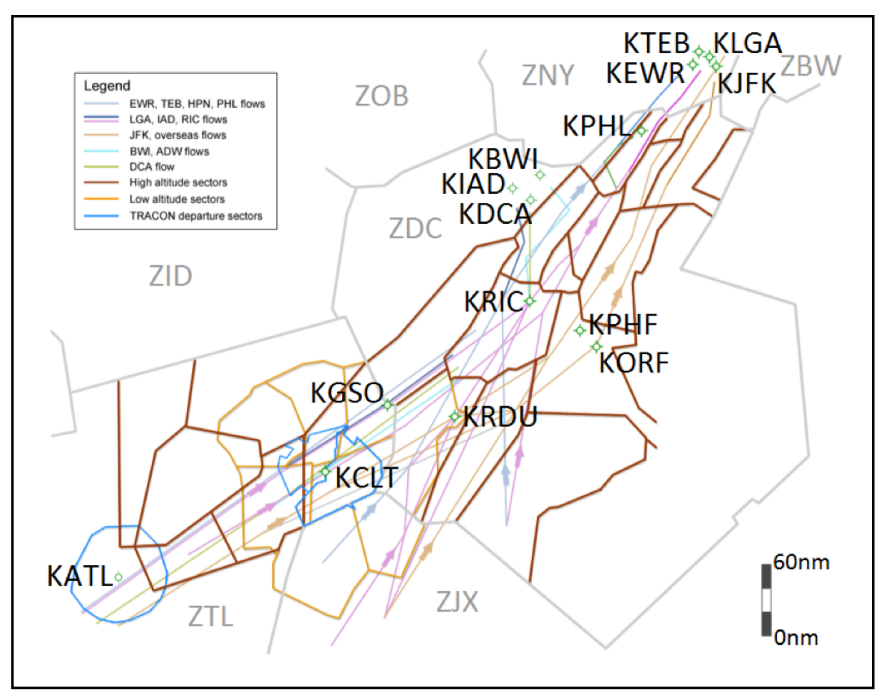

Fig. 8. Map of Washington Center with surrpounding ARTCCs. (showing major airports, jetways, and the TRACON areas for CLT and ATL.)

Simulation scenarios for the ZDC TMC were designed to have heavy traffic going to multiple destinations. There were 406 overflights in the South-flow scenario and 401 in the Northflow scenario. All of these aircraft were on, or joined, the jet routes shown in Fig. 8. In particular, the jet routes serving the seven airports that were being metered-to were designed to be busy, with over 130 aircraft scheduled to these locations, hence providing the requirement that multiple aircraft departing CLT should have APREQs. In addition to the approximately seven aircraft that the CLT TMC had to schedule with the ZDC TMC, confederates manually scheduled (APREQ) around 14 aircraft from other airports close to CLT (Dulles, Washington National, Baltimore, Richmond, Raleigh-Durham and Greensboro) and auto-scheduled an additional 10 flights from these airports into the flows for the seven major ZDC and ZNY airports to the north.

2) ZDC TMC participants: Three TMCs took part in the simulation, two were active FAA managers and one was retired. The Traffic Managers had 26.6 years of experience as controllers, on average (ranging from 12 to 35 years). In addition, they had an average of 17.6 years of experience as TMCs, ranging from 14 to 24 years. Two spent the majority of their careers at ZDC. Two confederates worked to depart traffic that required APREQs from the local airports around CLT.

3) ZDC TMC procedures: Unlike the other participants in the study, the ZDC TMCs were only asked to complete tasks related to metering and scheduling of APREQ flights, which are just a portion of the tasks that they would normally complete in their role in the field. In the demonstration, the TMCs were asked to manage the seven traffic schedules, for the seven airports that were in a metering status (La Guardia, Dulles, Washington National, Newark, Baltimore, Philadelphia and Kennedy), i.e., had heavy traffic flows. Although the confederates scheduled some aircraft manually, they also scheduled some electronically and TMCs were able to try the electronic APREQ scheduling tool in STBO to find times for all six/eight of the CLT departures requiring APREQ. 


\section{Data Collection}

The HITL was run over three consecutive days. The first half-day was devoted to training, acquainting the participants to the simulation environments and procedures; most of the participants had prior experience with the ATD-2 tools. In the afternoon of the first day of data collection, participants began working the first of the nine data collection runs. They completed questionnaires at the end of each run, as well as a post-simulation questionnaire. The last session on the third day was a debrief that provided an additional opportunity for participants to offer feedback.

Each simulation run lasted for approximately an hour $(M=$ $58.5 \mathrm{~min}$, ranging from 50.2 to $67.2 \mathrm{~min}$ ) and consisted of a build-up period as traffic began to flow into the facilities, approximately 40 minutes of stable, high traffic demand and a decline in traffic for the last 5-15 minutes of the run. The airport configuration (North vs. South operations) was, in most cases, switched from one run to the next.

Data were collected from workstation logs. Video and audio recordings were made at the controller workstations. Controller responses to the surveys and debrief discussions were recorded. Due to an inability to complete the final run with all participants, only the first eight runs are considered for data analysis.

\section{FINDINGS}

Findings reported in this paper are mostly of an anecdotal nature. There were too few participants and too few runs to provide statistical power, but the HITL was successful in revealing ATD-2 IADS system procedural changes, interface and software needs and trends, and overall feedback about the tools. Workload and situational awareness, while collected for all participants in the HITL, are not reported here; the ATC Tower TMC duties were reduced in the HITL compared to operational world duties and thus workload and situational awareness for the ATC Tower were not useful. Additional findings pertaining to the metering of traffic from pushback in the Ramp are reported in [5].

\section{A. Scheduling APREQ/CFR Release Times}

Participants were able to schedule release times for a total of 54 flights with APREQ restrictions during the eight scenarios. When a flight was capable of electronic coordination, the participant chose to request an APREQ release time by choosing a slot from the timeline themselves $56.8 \%$ of the time. However, examination of the trend for how participants used each method of requesting a release time shows that as the runs progressed, the use of "Select Slot on Timeline" decreased and the use of "Request Release Time" increased (Fig. 9). This is a desired outcome because it suggests that users were increasingly more comfortable with the automation selecting the release time for them.

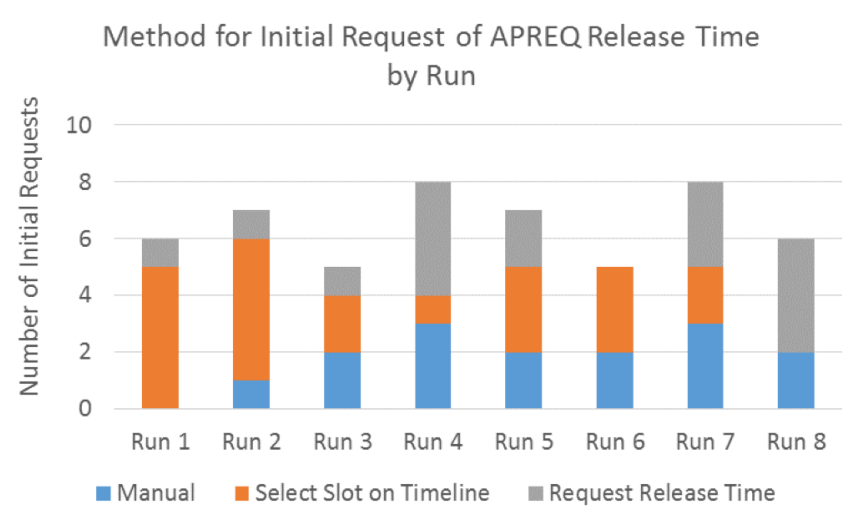

Fig. 9. Method for initial request of APREQ release time by run.

The end of study surveys asked the ATC Tower TMC participants how using the electronic APREQ tool during the simulation affected their coordination with the ZDC TMC compared to current day verbal coordination. Responses were collected on a scale of 1 (much less efficient) to 5 (much more efficient). Overall, the use of the electronic APREQ coordination with ATD-2 tools was rated more efficient than current day APREQ/CFR coordination $(M=5, S D=0$; Fig. 10). Participants were also asked how having access to the STBO Client affected their coordination with the ZDC TMC. Responses were collected on a scale of 1 (worsened coordination) to 5 (improved coordination). Ratings showed participants felt that using the STBO Client improved their coordination with the ZDC TMC $(M=4.8, S D=0.5$; Fig. 11).

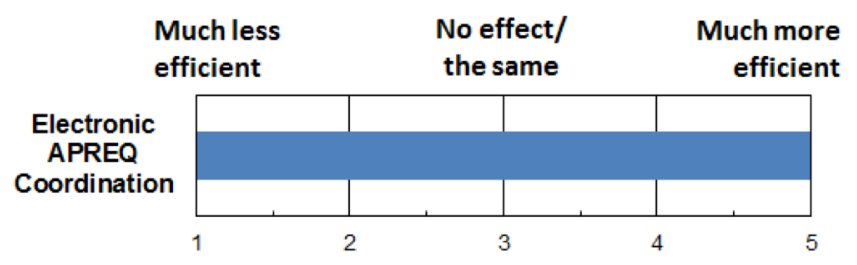

Fig. 10. Post-HITL rating of the level of efficiency of electronic APREQ coordination with the ZDC TMC using the electronic APREQ coordination. (compared with current day APREQ/CFR procedures.)

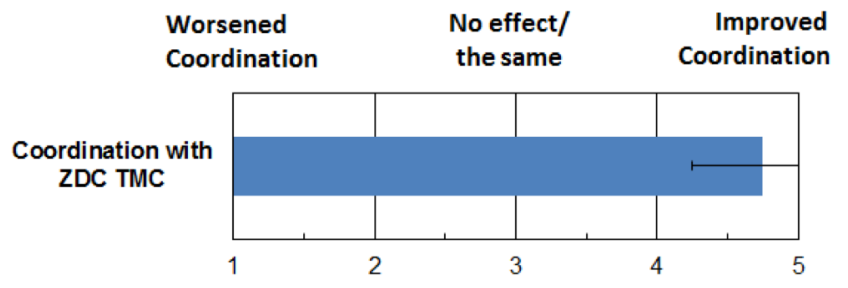

Fig. 11. Post-HITL rating of the level of improvement of APREQ coordination with the ZDC TMC using the electronic APREQ coordination. (compared with current day APREQ/CFR procedures.)

The ATC Tower TMC participants engaged in renegotiation of APREQ release times for flights 12 times across 54 flights; two of those 12 renegotiations was each a third negotiation for a flight (see Table I). For 10 of the 12 renegotiations (83.3\%), the TMC participant opted to "Select Slot on Timeline", with $40 \%$ of the original coordination completed using "Request Release 
Time", demonstrating that TMCs had to reschedule their own requested release times more often than release times chosen by the ATD-2 IADS system. When asked post-run about the effectiveness of the APREQ rescheduling process on a scale of 1 (very ineffective) to 5 (very effective), participants rated the APREQ rescheduling process to be very effective $(M=4.7, S D$ $=0.8$ ). Participants were also asked to rate the complexity of rescheduling an APREQ release time during the simulation. Responses were collected on a scale of 1 (very complex) to 5 (not very complex). Ratings showed that participants found the ATD-2 IADS tools easy to use for both electronic renegotiation $(M=5, S D=0)$ and verbal renegotiation $(M=4.5 ; S D=0.6)$ of APREQ release times (Fig. 12).

Overall, 15 flights that had APREQ restrictions also had EDCT restrictions. If a flight capable of electronic coordination had both an APREQ and an EDCT restriction, there was no difference in how participants chose to request a release time for that flight. TMCs were able to schedule APREQ release times for nine of those flights within the compliance window for the flights' EDCT. The APREQ release times for two of the flights were scheduled earlier and the other four were scheduled later than the EDCT compliance window.

TABLE I. METHOd OF RENEGOTIATING RELEASE TIMES

\begin{tabular}{|l|c|c|c|c|}
\hline \multirow{2}{*}{$\begin{array}{c}\text { Original } \\
\text { Release Time } \\
\text { Request }\end{array}$} & \multicolumn{2}{|c|}{$\begin{array}{c}\text { Second Release Time } \\
\text { Request }\end{array}$} & \multicolumn{2}{c|}{$\begin{array}{c}\text { Third Release Time } \\
\text { Request }\end{array}$} \\
\cline { 2 - 5 } & $\begin{array}{c}\text { Request } \\
\text { Release } \\
\text { Time }\end{array}$ & $\begin{array}{c}\text { Select Slot } \\
\text { on } \\
\text { Timeline }\end{array}$ & $\begin{array}{c}\text { Request } \\
\text { Release } \\
\text { Time }\end{array}$ & $\begin{array}{c}\text { Select Slot } \\
\text { on } \\
\text { Timeline }\end{array}$ \\
\hline $\begin{array}{l}\text { Request } \\
\text { Release Time }\end{array}$ & 2 & 2 & 0 & 1 \\
\hline $\begin{array}{l}\text { Select Slot on } \\
\text { Timeline }\end{array}$ & 0 & 5 & 0 & 1 \\
\hline Verbal & 0 & 1 & 0 & 0 \\
\hline
\end{tabular}

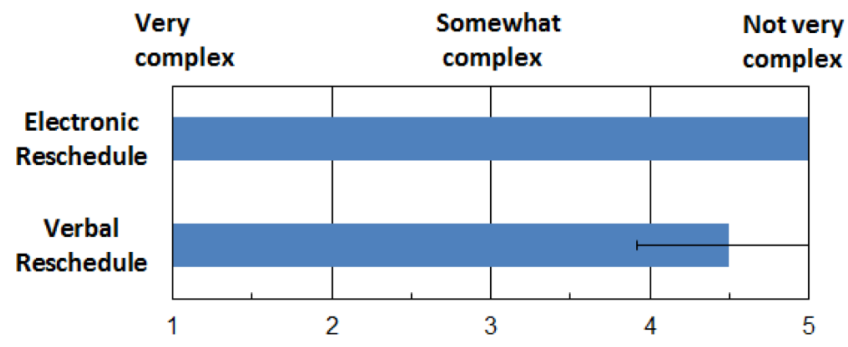

Fig. 12. Post-HITL rating of the complexity of rescheduling an APREQ release time. (electronic coordination vs. verbal coordination. with manual entry of release times into the STBO Client)

\section{B. APREQ/CFR Compliance}

Of the 54 flights with APREQ restrictions across all eight scenarios, only 24 were scheduled with release times that enabled the flight to take off before the end of the scenario and therefore be examined in regards to compliance. Fifteen of those flights had only an APREQ restriction. Two-thirds of those flights with only the APREQ restriction departed in compliance with their APREQ release times; the other third departed early.

TABLE II. APREQ COMPLIANCE

\begin{tabular}{|l|c|c|}
\hline \multirow{2}{*}{$\begin{array}{c}\text { Take Off Time in relation to } \\
\text { APREQ Compliance Window }\end{array}$} & \multicolumn{2}{|c|}{$\begin{array}{c}\text { Number of Flights by } \\
\text { Restriction Type }\end{array}$} \\
\cline { 2 - 3 } & APREQ only & $\begin{array}{c}\text { APREQ }+ \\
\text { EDCT }\end{array}$ \\
\hline Early & 6 & 6 \\
\hline Inside Window / On Time & 9 & 3 \\
\hline Late & 0 & 0 \\
\hline
\end{tabular}

Of all 24 flights that were able to take off before the end of the scenario, nine also had an EDCT restriction. Three flights departed inside of their APREQ compliance window, and six flights departed earlier than their APREQ compliance window. Of those same nine flights with both an APREQ and EDCT restriction, four departed within their EDCT compliance window and five departed earlier than their EDCT compliance window. Of all APREQ flights that departed, not a single flight departed later than its APREQ or EDCT compliance windows.

\section{Surface Delay}

While scheduling APREQ/CFR release times, delay is incurred when slots in the overhead stream are occupied by other flights. An examination of the final APREQ/CFR release times scheduled for all 54 APREQ/CFR flights during the HITL found that on average, 36.8 minutes $(S D=36.1$ minutes; Median $=$ 20.0 minutes; Fig. 13) of delay was added to APREQ flights. This large delay was anticipated since our scenario included dense overhead stream traffic. The location of where flights took their delay on the surface was spread across the entire airport surface. On average, 14.4 minutes $(S D=10.2$ minutes) of delay was taken at the gate. Beyond pushback, nine flights were assigned to wait out the delay in the general aviation ramp area, 13 flights waited on taxiways next to the runway but away from the rest of the runway queue, and only one flight was sent to the hardstand to wait out its delay.

TABLE III. LOCATION WHERE APREQ DELAY WAS TAKEN AFTER PUSHBACK

\begin{tabular}{|l|c|}
\hline $\begin{array}{c}\text { Location Where Flights Took } \\
\text { Some of Their APREQ Delay } \\
\text { After Pushback }\end{array}$ & $\begin{array}{c}\text { Number of Flights that } \\
\text { Took Some Delay at } \\
\text { the Location }\end{array}$ \\
\hline General Aviation Ramp Area & 9 \\
\hline Runway adjacent taxiways & 13 \\
\hline Hardstand & 1 \\
\hline
\end{tabular}




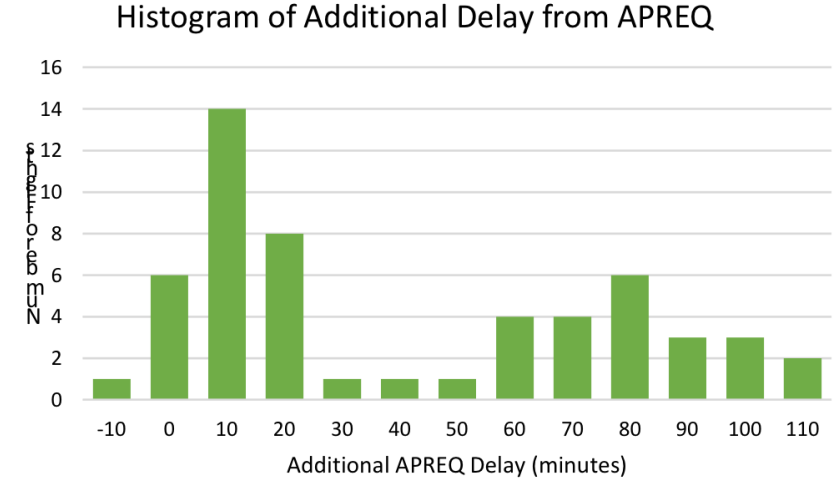

Fig. 13. Additional delay created by final APREQ/CFR release time. (the amount of delay added when scheduling an APREQ/CFR flight into the overhead stream, based on the final negotiated release time. )

\section{Feedback}

Participant feedback from the HITL demonstration included APREQ/CFR usability and procedural improvements for the ATD-2 tools. Usability improvements to the system mainly consisted of adjusting the compliance indicators for additional saliency between APREQ and EDCT release time compliance and the desire for an addition of an APREQ-only flight information table. In regards to procedural improvements, participants expressed the need for features such as:

- The ability to exclude individual flights from an APREQ restriction.

- Implementing audible alerts for specific APREQ events.

- Adjustments to the acknowledgement procedures for APREQ times sent back from the Center.

- Removal of the "thumbs up" ready icon from APREQ/CFR flights due to a change in procedure for when pilots call $\mathrm{CD}$ to receive a release time.

\section{DISCUSSION}

While the findings in this paper are limited due to the inadequate sample size in the HITL, they present a case that the use of IADS capabilities improved APREQ/CFR procedures and TMI compliance. As demonstrated by the increased use of "Request Release Time" throughout the HITL, user trust in the automation trended toward increasing. TMC users favored the "Select Slot on Timeline" over the "Request Release Time" option when requesting a different release time for a flight, possibly due to the additional control the option provides in choosing slots. On the whole, participants rated the ATD-2 IADS system's APREQ/CFR coordination as more efficient and a general improvement compared with current day APREQ/CFR procedures.
Overall, there was an increase in APREQ/CFR compliance as compared to those findings from the benefits analysis done for 2014 operations at CLT [2]. In the 2014 data, of the aircraft that were not in compliance with their APREQ restriction, more than half were early and the rest were late. While using the IADS system, APREQ compliance increased on the whole and flights outside of the compliance window were early, with not a single flight departing later than its APREQ compliance window. According to subject matter expert feedback, early release of APREQ and EDCT flights is acceptable compared to late release of those flights; it is easier to delay a flight after takeoff rather than speeding it up once airborne in order to reach a meter point at a specified time.

Since the HITL, the participant feedback described in this paper has been incorporated into the STBO Client. The set of APREQ procedures for ATD-2 can be used in the field at CLT and are likely to improve based on continued collaboration with ATD-2 users, partners, and stakeholders and the operational environment.

\section{ACKNOWLEDGMENT}

Thanks to James Park (California State University, Long Beach), 2017 summer intern at NASA Ames Research Center, for coding HITL data.

\section{REFERENCES}

[1] E. Ray, Order JO 7110.65 W. US Department of Transportation, Washington, DC, 2015.

[2] R. Coppenbarger, Y. Jung, T. Kozon, A. Farrahi, W. Malik, H. Lee, et al., "Benefit Opportunities for Integrated Surface and Airspace Departure Scheduling: A study of operations at Charlotte-Douglas International Airport," 35th Digital Avionics Systems Conference (DASC), Sacramento, CA, September, 2016.

[3] S. Engelland, A. Capps, K. Day, M. Kistler, F. Gaither, and G. Juro, "Precision Departure Release Capability (PDRC) Final Report," NASA/TM-2013-216533, June 2013.

[4] E. Chevalley, B. Parke, J. Kraut, N. Bienert, F. Omar, and E. Palmer, "Scheduling and Delivering Aircraft to Departure Fixes in the NY Metroplex with Controller-Managed Spacing Tools," 15th AIAA Aviation Technology, Integration, and Operations (ATIO) Conference, Dallas, TX, 2015.

[5] S. Verma, H. Lee, V. Dulchinos, E. Chevalley, L. Martin, K. Jobe, et al., "Evaluation of a Tactical Surface Metering Tool for Charlotte Douglas International Airport via Human-in-the-Loop Simulation," IEEE/AIAA 36th Digital Avionics Systems Conference, St. Petersburg, FL, September, 2017, in press.

[6] F. Chinn, "Building Airport Surface HITL Simulation Capability," 2016.

[7] T. Prevôt, N. Smith, E. Palmer, T. Callantine, P. Lee, J. Mercer, et al., "An Overview of Current Capabilities and Research Activities in the Airspace Operations Laboratory at NASA Ames Research Center," AIAA-2014-2860, $14^{\text {th }}$ AIAA ATIO Conference, Atlanta, GA, June, 2014 